\title{
Selected glaucoma risk factors and their role in disease progression. Part I - systemic, local and mechanical factors
}

\section{Wybrane czynniki ryzyka jaskry i ich rola w progresji choroby. Część I - czynniki ogólne oraz głównie miejscowe i mechaniczne}

\author{
Joanna Kośny, Piotr Jurowski \\ Department of Ophthalmology and Visual Rehabilitation, Medical University of Lodz, Poland \\ Head: Professor Piotr Jurowski, PhD, MD
}

\begin{abstract}
Ahstract:
The aim of this article is to summarise recent knowledge regarding selected glaucoma risk factors and to provide a brief description of the possible interaction mechanism. The article mostly refers to the most common disease variant - primary open angle glaucoma and focuses on systemic factors as well those altering local condition and mechanical properties of involved structures.

Key words: $\quad$ glaucoma, primary open angle glaucoma, local glaucoma risk factors, mechanical glaucoma risk factors.

Ahstrakt: $\quad$ Celem tego artykułu jest streszczenie najnowszej wiedzy o wybranych czynnikach ryzyka jaskry oraz krótki opis możliwych mechanizmów ich działania. Artykuł skupia się na najczęstszym wariancie choroby - jaskrze pierwotnej otwartego kąta, oraz czynnikach ogólnych i tych, które mają wpływ przede wszystkim na aspekt lokalny i mechaniczny.

Stowa kluczowe: jaskra, pierwotna jaskra otwartego kąta, lokalne czynniki ryzyka jaskry, mechaniczne czynniki ryzyka jaskry.

The authors declare no conflict of interest/ Autorzy zgłaszają brak konfliktu interesów w związku z publikowaną pracą
\end{abstract}

\section{Introduction}

Glaucoma is the most common cause of irreversible loss of sight worldwide (1). The term "glaucoma" encompasses a heterogeneous group of diseases with likely varying risk factors. Estimated global prevalence of glaucoma will reach 80 million in 2020. The most common variant is open-angle glaucoma (global prevalence of $3.1 \%$ versus $0.5 \%$ in primary angle closure glaucoma) (1). Therefore, the article focuses mainly on factors affecting primary open angle glaucoma (POAG).

The most recognized risk factor of glaucoma is elevated intraocular pressure (IOP). However, there is a range of other factors affecting the disease and unfortunately, a large proportion of them are still poorly understood (1). The factors discussed below are potentially linked to the two main proposed theories of damage to the retinal ganglion cells (RGCs) and retinal nerve fibre layer (RNFL), resulting in glaucomatous optic neuropathy (GON). Those are a mechanical and a vascular theory (2). In brief, the mechanical theory postulates that elevated intraocular pressure (IOP) stretches and damages lamina cribrosa (anatomical structure which RCG axons pass through as they exit the eye). On the other hand, according to the vascular theory, GON is supposedly associated with inadequate perfusion due to primary or secondary vascular reasons (as a consequence of raised IOP or presence of other risk factors) (2).

The aim of this article is to summarize some of the less obvious glaucoma risk factors including, where possible, a short description of the possible interaction mechanism. The risk fac- tors analysed below are primarily implied in both mechanical and vascular mechanism of glaucoma, with more significant effect on one of the domains. This article focuses mainly on systemic factors as well those altering local condition and mechanical properties of involved structures.

\section{Ethnicity}

The prevalence of glaucoma in total as well as primary open-angle glaucoma alone is the highest in African ethnic groups (1). Meta-analyses showed that highest incidence of POAG in people of African descent starts from early middle age. As a result, disease exposure is fairly long, which may explain why POAG is more severe in the elderly Black population compared to Caucasian population of matching age. On the other hand, primary angle closure glaucoma (PACG) occurs more often in Asian populations (over $80 \%$ of cases worldwide) $(1,3)$.

Despite clear statistical data, an obvious explanation of these trends is still lacking. The proposed ethnicity-derived underlying causes of POAG include anatomical and pigmentation differences as well as genes (4). Higher prevalence of cardio-metabolic diseases in Black and Asian populations compared to Caucasian populations should also be considered (4). In terms of acute angle closure, its significantly higher prevalence in Eskimo population, even compared to Chinese populations, was attributed to anatomical factors - e.g. shallower central and peripheral anterior chamber, shorter ocular axial length and thicker lens (5). 


\section{Sex}

Although it has been unclear whether sex affects glaucoma prevalence, the recent meta-analyses suggest that primary open angle glaucoma is more common in men $(1,4)$. Postulated reasons for higher POAG prevalence in men are both anatomical (differences in retinal nerve fibre thickness) and systemic (higher prevalence of cardiovascular diseases in men) (4). Some evidence shows that hormones can possibly trigger genetic expression of exert some protective effect. Oestrogens supposedly reduce risk of POAG on different levels - they may, for example, affect IOP, modulate extracellular matrix production and exert neuroprotective effect $(4,5)$.

On the other hand, it is observed that in some populations (such as Eskimo and Chinese and a few other Asian ethnic groups), women are at higher risk of acute angle closure (5). Some authors imply its anatomical explanation, that is, women have shallower anterior chambers compared to men (5).

\section{Hypothyroidism}

Research provides conflicting results regarding the link between hypothyroidism and glaucoma. Two recent reviews and meta-analyses $(6,7)$ showed that the risk of glaucoma is significantly higher in patients with hypothyroidism - one of them analysed glaucoma in general (6) and another one POAG only (7). On the other hand, there is no increased risk of hypothyroidism in patients with glaucoma (6).

According to a hypothesis postulated by Smith et al. (1992), hypothyroidism is associated with increased deposition of mucopolysaccharides and hyaluronic acid in the trabecular meshwork, which leads to decreased aqueous outflow and results in intraocular pressure elevation $(6,7)$. Additionally, both conditions might be linked with autoimmunity and there is a possibility of shared genetic autoimmune predisposition (6). Furthermore, a common denominator of both diseases can be their shared risk factors (sex, age, environmental factors) (6).

\section{Genetics}

There is a number of genes possibly involved in the pathogenesis of glaucoma. As discussing them all is well beyond the scope of this article, only a few important ones will be briefly described.

Matrix Gla protein gene (MGP) encodes a protein expressed mainly in cartilage and vascular smooth muscle cells. Its polymorphisms are known to be associated with coronary artery calcification. Inactive MGP is correlated to increased arterial stiffness (8). MGP protein was identified in trabecular meshwork, the ciliary muscle and immediate sclera above the Schlemm's canal as well as peripapillary sclera around the optic nerve. In healthy subjects, it may play a part in maintaining elasticity and preventing calcification. The erratic MGP expression probably induces stiffness of these tissues - in the first case, reducing aqueous outflow, and in the latter, increasing stress on the optic disc (8).

It was found that MGP RNA levels are lower in trabecular meshwork of patients with glaucoma, which was concomitant with higher levels of calcification markers. However, there is no sign of calcific plaques in trabecular meshwork of glaucomatous eyes as might have been predicted with an increased calcification process (8).
Myocilin (MYOC) gene or trabecular meshwork induced glucocorticoid response (TIGR) gene variations are linked with glaucoma (9). In the eye, MYOC is expressed in the iris, retina, trabecular meshwork, and cornea. Mutations causing excessive production and insufficient degradation of the MYOC protein result in its accumulation in the trabecular meshwork, which impacts aqueous fluid drainage and leads to IOP elevation (9). MYOC is probably involved in a large number of processes including cell migration, protein trafficking, receptor-mediated endocytosis, programmed cell death, cytoskeleton functions and optic nerve myelination $(9,10)$. Treatment with glucocorticoids was found to increase TIGR expression. This mechanism could be responsible for IOP raise in response to glucocorticoids in patients with glaucoma (11). Certain mutations of MYOC account for the autosomal dominant POAG variant in juvenile-onset glaucoma. Glaucoma variants caused by MYOC gene depend on mutation type and are mostly severe, requiring surgical management but can also present as an adult onset disease of lower severity (9). MYOC is expressed not only in the eye but in different tissues, as well. However, glaucoma is the only identified disease linked to its mutations (9). MYOC-associated glaucoma mechanisms may be interfered with by another gene, CYP1B1, but the exact mechanism is uncertain $(9,10)$.

Optineurin (OPTN) gene variants, mostly missense mutations, result in NTG $(9,10)$. Optineurin is a multifunctional Rab-binding protein involved in cell shape changes and included in the TNFa-signaling NFkB pathway. By inhibiting TNFa-induced NF-kB activation, it influences the apoptosis threshold $(9,10)$. It is involved in many processes including autophagy, host defence against pathogens, transferrin receptor transport and degradation, cell division and protection against oxidative stress $(9,10)$. Its mutation in glaucoma results in interrupted transferrin receptor recycling (10). In animal models. it leads to age-dependent loss of RGCs and visual impairment despite normal IOP (9).

OPTN probably shares pathogenic pathway with TBK1 gene. They are both likely included in regulating the process of damaged mitochondria autophagy. TBK1 is a gene encoding serine/ threonine kinase, involved in control of inflammatory responses to foreign agents. Its duplication is associated with normal tension POAG (around 1\% of cases) (9). Animal model showed that TBK1 gene duplication leads to RCG loss despite normal pressure. Nevertheless, it is uncertain how erratic autophagy associated with OPTN and TBK1 leads to NTG changes (9). Furthermore, both OPTN and TBK1 mutations were reported in CNS disorders such as amyotrophic lateral sclerosis (ALS) (9).

\section{Eye refraction}

Many studies debate whether myopia is actually a risk factor for glaucoma $(11,12)$. Currently, research shows conflicting data on correlation between refractive error and IOP levels $(11,12)$. However, a significant number of studies indicate that myopia, especially high myopia, is a risk factor for POAG $(11,12)$. For instance, according to the Blue Mountains Eye study, patients with myopia are two to three times more likely to develop glaucoma (12).

Whereas the link between glaucoma and myopia remains under investigation, the two main hypotheses are the hyper- 
tension gene theory and the collagen-related gene theory (11). Firstly, both patients with high myopia and those with glaucoma are much more likely to respond to glucocorticoids with IOP elevation, as compared to other individuals (approximately $90 \%$ vs. $5 \%$ ) (11). Therefore, a common mechanism of trabecular meshwork cell protein hypersensitivity to glucocorticoids was proposed (11). One of the established genes implicated in the interaction between trabecular meshwork and glucocorticoids in glaucoma is MYOC/TIGR gene already mentioned above. It is suggested that a similar mechanism may be present in high myopia (HM). However, studies show conflicting data on whether MYOC/TIGR gene polymorphism is associated with $\mathrm{HM}$ and more research is required to better understand the link in question (11).

Secondly, it is well established that changes in collagen structure of the eye are common for both HM and glaucoma (11). However, HM is possibly associated with abnormal scleral collagen, whereas glaucoma is linked to collagen changes within the optic disc and the lamina cribrosa, which impair the resistance of the latter against deformation caused by intraocular pressure. Abnormal collagen may also impair optic nerve fibre protection against injuries which may eventually lead to changes seen in glaucoma (11). Even though studies failed to identify a certain gene causing collagen abnormality in both HM and glaucoma, there is certainly room for future research (11).

In terms of biomechanical factors, myopic eyes with bigger optic discs are more susceptible to glaucoma (12). The major site of retinal ganglion cell injury in glaucoma is lamina cribrosa (12). It is a structure composed of scleral connective tissue, which, due to its porosity, enables passage of retinal ganglion cell axon bundles and blood vessels (13). It is postulated that stretched and thinner lamina cribrosa together with elongated and thinned peripapillary tissue may augment the degree of optic nerve change (1). Connective tissue abnormalities in eyes of longer axial length contribute to an increase in shearing forces in the lamina cribrosa compared to forces acting on shorter axial length orbits. This might increase the susceptibility of the nerve at any IOP (12). Furthermore, axial length in myopia is associated with posterior deformation of Bruch's membrane, which may be linked to glaucomatous damage (12). Confocal scanning laser ophthalmoscopy also demonstrated that disc height tends to decrease with myopia which results in compact RGC axons (12). Furthermore, long axis myopic eyes seem to exhibit reduced RNFL thickness (12). Another mechanical risk factor in myopia involves ocular movement-related pulling of peripapillary sclera by optic nerve dura matter, which adversely affect the lamina cribrosa (1).

The relationship between HM and glaucoma, though, is even more complex. In some cases, elevated IOP may be a causal factor for HM (11). On the other hand, thinner sclera in HM increases susceptibility to IOP, resulting in further eye elongation and potential optic nerve impairment. This may possibly lead to HM progressing towards open angle glaucoma (11). Another aspect is a similarity of structural and functional changes in glaucoma and high myopia in eyes with long axial length, which makes it difficult to distinguish between the conditions (11). Myopia precludes accurate assessment of cup to disc ratio, mostly due to optic disc tilt (11). Other complicating factors inc- lude unclear disc excavation and bigger cup typical of HM (11). Furthermore, glaucoma in $\mathrm{HM}$ may be present despite relatively low IOP, as baseline IOP in HM may be low (11). Retinochoroidal atrophic changes in HM may also interfere with detection of glaucoma related atrophy (11). Additionally, certain typical signs of glaucoma, such as vessel bayoneting and translocation, might be absent in myopic eyes with long axial length due to tissue traction (11). Specificity and sensitivity of RNFL evaluation is also impaired, as RNFL thickness is proportional to axial length (12). All above mentioned circumstances affect diagnostic evaluation and progression assessment of glaucoma in $\mathrm{HM}$ $(1,11,12)$. Therefore, researchers suggest a few methods as alternatives to inaccurate structural assessment - visual field defect progression monitoring, RNFL thickness measurement in certain regions (superior and inferior pole peripapillary RNFL is thinner in myopic eyes) (11), ganglion cell complex to macular outer retinal thickness ratio (no correlation with refractive error) (12).

On the other hand, hyperopic eyes have a higher chance of developing both acute and chronic angle-closure glaucoma $(1,12)$. The reason for this is the structure of the eye - shallower anterior chamber, thicker lens located anteriorly with significant anterior lens vault and thicker iris (1). These factors increase risk of anterior chamber angle closure with peripheral iris in mid-mydriasis (1). It should be noted, though, that angle closure glaucoma in myopic eyes is not impossible (12).

\section{Intracranial pressure/translaminar pressure difference}

The optic nerve is exposed to two types of pressure the IOP inside the eye and cerebrospinal fluid (CSF) pressure within the subarachnoid space, also known as intracranial pressure (ICP) (14). The lamina cribrosa, anatomically being the floor of the optic disc, is an important structure as it separates these two zones of pressure influence $(13,14)$. Changes in pressure (IOP or ICP) in the two compartments affect pressure distribution, axial forces and transverse tension across the optic disc (13). The difference between the two pressures is referred to as translaminar pressure difference (TPD) and is physiologically low, with IOP slightly higher than CSF pressure (14). Therefore, both normal IOP with low ICP as well as elevated IOP with normal ICP result in the same TPD (15). TPD is also influenced by the thickness of the lamina cribrosa, which is thinner in high myopia and advanced glaucoma (201 microns in glaucoma vs. 457 microns in healthy patients) $(14,15)$. This might explain why patients with high myopia and advanced glaucoma are at risk of more dramatic glaucoma progression (13). On the other hand, lamina cribrosa is thicker in ocular hypertension, which is possibly linked to the absence of glaucomatous damage (13).

In a meta-analysis, Siaudvytyte et al. demonstrated that patients with POAG, especially normal tension glaucoma, had significantly lower ICP than healthy controls. TPD, on the other hand, was twice as high in NTG and almost five times as high in high tension glaucoma as in healthy controls (14). However, quoted studies have some limitations, such as uncertainty whether the lumbar puncture CSF pressure measurement can yield actual CSF pressure value in the orbit around the optic nerve. There is also lack of clarity regarding the degree of interference 
from patient positioning upon measurements. The invasiveness of lumbar puncture is a significant drawback both in research and clinical practice (14). New possibilities arise with the advent of of non-invasive ICP measurement methods, such as two-depth transcranial doppler based technology (15).

A number of studies show, as well, that decreased ICP may be linked to the increased cup to disc ratio and worsening of glaucomatous optic neuropathy in normal tension glaucoma, while elevated ICP to act as a protective factor against glaucomatous damage as is likely the case in individuals with ocular hypertension $(13,16)$. Additionally, ICP decreases with age and POAG is more common in older population. Furthermore, ICP tends to increase with the BMI and elevated BMI was found to be linked to the lower incidence of POAG in females with normal IOP. Therefore, these ICP-modified factors may also correlate with glaucomatous damage (16).

A possible mechanism of more severe TPD-related damage to the optic nerve involves a disturbance to axonal transport and blood flow, as well as changes to the shape of the lamina cribrosa (14). For instance, elevated IOP concomitant with low ICP causes posterior bowing of the lamina cribrosa which disrupts physiological orthograde axoplasmic transport within the optic nerve (16).

Furthermore, it is suggested that ICP fluctuations may be linked to TPD fluctuations and therefore possibly cause glaucomatous optic nerve damage through repetitive shear stress in the lamina cribrosa (14). On the other hand, it was observed that by reducing or reversing TDP, the Valsalva manoeuvre decreased the cup to disc ratio and increased neuro-retinal rim parameters (14).

\section{Glymphatic flow restriction}

A theory by Wostyn et al. links glaucomatous changes with restriction of glymphatic flow within the lamina cribrosa influenced by above mentioned decreased ICP and increased TPD (13). Firstly, it has been reported, based on animal models, that beta-amyloid likely acts as a mediator in the retinal ganglion cell death induced by pressure, therefore resembling at the molecular level Alzheimer's Disease (AD) (13). Following this finding, researchers suggested future possibility of glaucoma treatment that would target beta amyloid (13).

Secondly, recent research by Wostyn suggests a possible paravascular transport system within the retina, similar to the glymphatic system newly found in the brain. The name glymphatic system entails its functional resemblance to the peripheral lymphatic system alongside reliance on astroglial water transport. This proposed system is likely involved in clearing solutes from the interstitial fluid in the optic nerve, including eliminating neurotoxins induced by raised IOP such as beta amyloid (13). Thus, it might be of importance in glaucomatous optic neuropathy pathogenesis (13). Furthermore, it was suggested that low ICP together with a high translaminar pressure gradient resulting from elevated IOP and/or thin lamina cribrosa might impair the glymphatic flow from paravascular spaces within the optic nerve to intraocular retinal paravascular spaces. As a result, neurotoxin elimination is reduced, which leads to glaucomatous nerve damage (13).

In terms of the link between glaucoma and $A D$, research suggests that have the prevalence of glaucoma in patients with $A D$ is higher than in the general population $(23-25 \%$ vs. $5-9 \%)(10)$. It seems that RGCs in $A D$ are more sensitive to IOP-induced damage (10). On the other hand, Blanks et al. postulated that neuronal cell death in ganglion cell layer should be viewed as an $A D$ manifestation along with well recognized changes in the cerebral cortex and hippocampus which cause short term memory loss (10).

\section{Conclusion}

The factors discussed in the paper are just a small selection of potential glaucoma risk factors. Many studies provide either conflicting or inconclusive data. Therefore, further research in many areas is needed. Nevertheless, new promising concepts such as translaminar pressure difference or glymphatic theory are being developed. Hopefully, future work will provide deeper insight into glaucoma pathogenesis. Better understanding of disease aetiology will hopefully entail development of mechanism - oriented, effective treatment. The ultimate goal is to save the sight of millions of patients.

\section{References:}

1. Jonas JB, Aung T, Bourne RB, Bron AM, Ritch R, Panda-Jonas S: Glaucoma. Lancet. 2017 Nov 11; 390(10108): 2183-2193 .

2. Flammer J, Orgül S, Costa VP, Orzalesi N, Krieglstein GK, Metzner Serra $\mathrm{L}$, et al.: The impact of ocular blood flow in glaucoma. Prog Retin Eye Res. 2002 Jul; 21(4): 359-393.

3. Cheng JW, Zong Y, Zeng Y-Y, Wei1 R-L: The prevalence of primary angle closure glaucoma in adult Asians: a systematic review and meta-analysis. PLoS One. 2014 Jul 24; 9(7): e103222.

4. Kapetanakis VV, Chan MP, Foster PJ, Cook DG, Owen CG, Rudnicka AR: Global variations and time trends in the prevalence of primary open angle glaucoma (POAG): a systematic review and meta-analysis. Br J Ophthalmol. 2016 Jan; 100(1): 86-93.

5. Tehrani S: Gender difference in the pathophysiology and treatment of glaucoma. Curr Eye Res. 2015 Feb; 40(2): 191-200.

6. Thvilum M, Brandt F, Brix TH, Hegedus L: The interrelation between hypothyroidism and glaucoma: a critical review and meta-analyses. Acta Ophthalmol. 2017 Dec; 95(8): 759-767.

7. Wang S, Liu Y, Zheng G: Hypothyroidism as a risk factor for open angle glaucoma: A systematic review and meta-analysis. PLoS One. 2017 Oct 25; 12(10): e0186634.

8. Borras T: $A$ single gene connects stiffness in glaucoma and the vascular system. Exp Eye Res. 2017 May; 158: 13-22.

9. Liu Y, Allingham RR: Major review: Molecular genetics of primary open-angle glaucoma. Exp Eye Res. 2017 Jul; 160: 62-84.

10. Doucette LP, Rasnitsyn A, Seifi M, Walter MA: The interactions of genes, age, and environment in glaucoma pathogenesis. Surv Ophthalmol. 2015 Jul-Aug; 60(4): 310-326.

11. Fei M, Dai J, Sun X: Progress in understanding the association between high myopia and primary open-angle glaucoma. Clin Exp Ophthalmol. 2014 Mar; 42(2): 190-197.

12. Hsu C, Chen RI, Lin SC: Myopia and glaucoma: sorting out the difference. Curr Opin Ophthalmol, 2015 Mar; 26(2): 90-95.

13. Wostyn P, Killer HE, De Deyn PP: Glymphatic stasis at the site of the lamina cribrosa as a potential mechanism underlying open-angle glaucoma. Clin Exp Ophthalmol. 2017 Jul; 45(5): 539-547 . 
14. Siaudvytyte L, Januleviciene I, Daveckaite A, Ragauskas A, Bartusis $\mathrm{L}$, Kucinoviene $\mathrm{J}$, et al.: Literature review and meta-analysis of translaminar pressure difference in open-angle glaucoma. Eye (Lond). 20150ct; 29(10): 1242-1250.

15. Siaudvytyte L, Januleviciene I, Ragauskas A, Bartusis L, Siesky B, Harris A: Update in intracranial pressure evaluation methods and translaminar pressure gradient role in glaucoma. Acta Ophthalmol. 2015 Feb; 93(1): 9-15.
16. Guy AH, Wiggs JL, Turalba A, Pasquale LR: Translating the Low Translaminar Cribrosa Pressure Gradient Hypothesis into the Clinical Care of Glaucoma. Semin Ophthalmol. 2016; 31(1-2): 131-139.

The paper was originally received 25.06.2017 (KO-00171-2018)/ Praca wpłynęła do Redakcji 25.06.2017 r. (KO-00171-2018) Accepted for publication 14.11.2018/ Zakwalifikowano do druku 14.11.2018 r.

\section{Reprint requests to (Adres do korespondencji):}

Joanna Kośny, MD

Klinika Okulistyki i Rehabilitacji Wzroku, USK im. WAM,

UM w todzi

ul. Żeromskiego 113

90-549 Łódź

e-mail: joannakosny@gmail.com

\section{Polskie Towarzystwo Okulistyczne e-mail: pto@pto.com.pl}

